\title{
Dignidad de la persona y funciones del Derecho constitucional*
}

\author{
Ignacio Gutiérrez Gutiérrez \\ Profesor Titular de Derecho Constitucional \\ Universidad Nacional de Educación a Distancia
}

Recibido: 30.03 .2011

Aceptado: 02.05 .2011

Resumen: El presente trabajo pretende mostrar en qué medida el Derecho constitucional y, en particular, "la dignidad humana" o "de la persona" a la que aluden diversos textos constitucionales pueden encauzar los debates jurídicos acerca de las expectativas abiertas por los avances científicos en materia de biotecnología. Al efecto, es preciso atender tanto las exigencias de estabilidad del orden constitucional como a la necesaria apertura del proceso democrático.

Palabras clave: Dignidad de la persona, funciones de la Constitución, interpretación constitucional, estabilidad y apertura de la Constitución.

Abstract: This paper tries to show to what extend Constitutional Law and,particularly, "human dignity" as a legal concept included in several constitutional documents may channel legal debates dealing with the growing expectations due to scientific developments in the biotechnology area. It is therefore required to take into account the needs for stability within constitutional order as well as the necessary openness of the democratic process.

Key words: Human dignity, constitutional tasks, constitutional interpretation, stability and openness of the Constitution.

I. Los progresos en el campo de la tecnología médica son de tal magnitud que cualquier ilusión parece al alcance de la mano; la ficción encuentra aquí dificultades para elevarse al plano de lo inverosímil. El estudio de las redes nerviosas y su aplicación al control cerebral de las prótesis mecánicas nos acercan al mundo de la película Avatar (James Cameron, 2009), en la que un cerebro humano coloniza un cuerpo ajeno, creado por cierto mediante una tecnología genética y reproductiva que tampoco nos parece ya demasiado extraordinaria. En Abre los ojos (Alejandro Amenábar, 1997, con versión americana de Cameron Crowe, Vanilla Sky, 2001), la mente humana era a su vez

* El presente artículo se integra en el proyecto de I+D del Ministerio de Educación (Investigación Fundamental) "Constitución y globalización: transformaciones del Estado constitucional y constitucionalización de espacios supranacionales" (DER2009-10375, 2010-2012), dirigido por Oscar Alzaga Villaamil. 
colonizada mediante un sueño fabricado artificialmente y dotado de verosimilitud en principio absoluta; el negativo de tal proyección puede verse en los ensayos de reprogramación de la memoria.

Los mencionados relatos juegan con expectativas creadas por los desarrollos científicos, desplazando los problemas planteados en presente a la frontera de lo ya intuido como posible. También de ese modo contribuyen a perfilar la conciencia colectiva en torno al procesamiento de tales avances, abiertos tanto al peligro como a la esperanza. La literatura, el teatro y el cine siempre han servido, en efecto, como catalizadores de las reacciones sociales frente a los nuevos tiempos, generando una conciencia social que sin duda influye en el desarrollo jurídico. Porque las expectativas que afectan a supuestos centrales de la convivencia colectiva (la identidad humana, la conciencia de libertad y responsabilidad, el instinto de supervivencia ...) deben ser gestionadas en democracia conforme a criterios legitimados en el foro público. La regulación jurídica sustantiva dependerá finalmente de las orientaciones morales y culturales que se impongan en él.

Corresponde al Derecho constitucional encauzar tal debate. Sobre la base, pues, de la opinión pública, se decide en sede parlamentaria; en el bien entendido de que la decisión mediante ley ha de dejar siempre abierta la prosecución de los debates, articulados e institucionalizados de conformidad con las exigencias del principio democrático.

Sin embargo, los procesos abiertos por los aludidos avances científicos se presentan a menudo como difícilmente reversibles; al menos en tales casos no parece aceptable que las correspondientes decisiones se adopten apelando al provisional principio mayoritario. Deben dotarse entonces de una estabilidad que, en el campo del Derecho, se asocia al orden constitucional material. Para incorporarse al cuerpo de la Constitución, el acuerdo debe gozar del respaldo que exigen las actuaciones del poder constituyente (originario o derivativo).

Pero apenas parece hoy posible alcanzar resultados en este terreno a través de un proceso orientado hacia el desarrollo de convicciones colectivas que, más allá incluso de las instituciones oficiales, comprometan a todos. Porque el disenso alcanza a los presupuestos metodológicos del debate, visto como una argumentación sea sobre principios susceptibles de ponderación, sea sobre límites morales absolutos. Límites que, por lo demás, se quieren ver reconocidos de antemano en el orden constitucional ya existente, como marco indisponible para las discusiones suscitadas por los nuevos desarrollos de la ciencia; si se han acelerado más allá de lo que el Derecho positivo, los juristas y el foro público parecen capaces de asimilar, es natural buscar una referencia estable por encima de tales procesos.

Por eso se invoca la dignidad humana en los debates científicos, éticos y políticos en torno a la investigación médica, con la esperanza de que, en cuanto norma central del ordenamiento constitucional positivo, le sea reconocido al argumento una específica fuerza normativa. Ahora bien, tal pretensión de estabilidad, postulada con relativa facilidad para ciertos enunciados 
abstractos, se enfrenta a grandes dificultades en el momento de su concreción; entonces, de uno u otro modo, termina por imponerse la necesidad de mitigar las exigencias del principio o de ponderar las circunstancias de su aplicación.

Puntos de equilibrio entre las posibilidades del debate público y las restricciones impuestas por las garantías constitucionales de índole material se buscaron afanosamente por ejemplo en Alemania con ocasión del debate acerca de la investigación con células-madre procedentes de embriones humanos fecundados in vitro, en el que intervinieron decisivamente los especialistas en Derecho constitucional ${ }^{1}$. Debates similares se desarrollan también en España, naturalmente; pero aquí suele quedar al margen la Constitución, como si nadie pensara que pudiera aportar criterio alguno. Lo cierto es que, en uno y otro país, se imputan al Derecho constitucional funciones diferentes; tampoco la garantía de la dignidad humana en el art. 1 de la Ley Fundamental y la mención de la dignidad de la persona en el art. 10.1 de la Constitución española resultan comparables.

Y, sin embargo, los fenómenos a los que nos referimos son transfronterizos y exigen soluciones compartidas. Las dificultades que comporta la regulación de procesos que con facilidad escapan a la acción territorializada del Estado se ponen de manifiesto con la globalización no sólo de los mercados financieros, sino también de los desarrollos científicos; y también en ese ámbito, por cierto, pretenden encontrar eco quienes aspiran a una "libre competencia" de ordenamientos jurídicos estatales. El debate nacional es, ya por ese solo calificativo, insatisfactorio; las propuestas constitucionales de ámbito estatal resultan insuficientes, y se necesitan por tanto principios de Derecho constitucional válidos para el conjunto de la Comunidad internacional ${ }^{2}$.

${ }^{1}$ Cfr. mi artículo «El debate alemán sobre la investigación con células-madre de origen embrionario», Teoría y Realidad Constitucional n ${ }^{\circ} 10-11$, págs. 533 ss. En él y especialmente en mi libro Dignidad de la persona y derechos fundamentales, Madrid-Barcelona: Marcial Pons, 2005, se apoyan las presentes reflexiones. Dado que ambos textos contienen ya abundantes referencias bibliográficas, reduciré aquí el aparato de notas a las estrictamente impuestas por la cita textual. De la bibliografía posterior han de mencionarse aquí los trabajos de M. Nettesheim, «Die Garantie der Menschenwürde zwischen metaphysischer Überhöhung und bloßem Abwägungstopos», AöR 130, págs. 71 ss., y H.-G. Dederer, «Die Garantie der Menschenwürde (Art. 1 Abs. 1 GG). Dogmatische Grundfragen auf dem Stand der Wissenschaft», JöR $(N F)$ 57, págs. 89 ss.

${ }^{2}$ Sobre las perspectivas abiertas al Derecho constitucional por la globalización y la multiculturalidad, que orientan el presente ensayo, pueden verse los libros Derecho constitucional para la sociedad multicultural (D. Grimm/E. Denninger, ed. por I. Gutiérrez Gutiérrez, Madrid: Trotta, 2007) y La constitucionalización de la Comunidad internacional (ed. por A. Peters/M. Aznar/I. Gutiérrez, Valencia: Tirant lo Blanch, 2010); cfr. también para nuestro tema por ejemplo Chr. McCrudden, «Human Dignity and Judicial Interpretation of Human Rights», EJIL 19, págs. 655 ss. 
Las diferencias en las regulaciones constitucionales entroncan con la diversa experiencia histórica en cuanto se refiere a la relación multipolar entre religión, ética, política y Derecho. Los distintos equilibrios que cada país halla provisionalmente para las tensiones resultantes de cada uno de los posibles binomios no necesariamente se compensan, como si se tratara de un campo de fuerzas que de algún modo tienden siempre a converger en torno a un punto central, sino que en ocasiones se potencian, como si la distancia total entre las culturas jurídicas resultara de la multiplicación de las distancias parciales de cada uno de los pares de puntos de equilibrio.

Los principios internacionales, en cualquier caso, no necesariamente se han de reducir al máximo común denominador representado por las posibilidades efectivas de acuerdo entre todos los Estados; en el Derecho internacional se reconocen postulados vinculantes que van más allá de tales condiciones restrictivas. Mas proponerlos para este ámbito supera con creces las pretensiones del presente estudio, que se limitará a explicar los diferentes contextos constitucionales de Alemania y España y a esbozar la distinta función que corresponde en cada uno de ellos al postulado de la dignidad humana, que desempeña un papel central en estos debates. El análisis de esas diferencias permitirá quizá comprender la naturaleza del reto que supone superarlas y orientar el empeño. Los diversos desarrollos en España y Alemania sirven aquí, por lo demás, sólo como ilustración de las dificultades que pueden surgir para configurar un orden supranacional que comprenda culturas jurídicas mucho más divergentes que las representadas por estos dos países, a fin de cuentas integrantes de una misma comunidad jurídica identificada por la Carta de Derechos Fundamentales de la Unión Europea y, ya en un plano superior, por el Convenio Europeo de Derechos Humanos.

II. La reflexión jurídica bien puede partir de un problema concreto, cual es por ejemplo el de la legitimidad de una intervención legislativa en la libertad de investigación científica, constitucionalmente garantizada en Alemania (art. 5.3 de la Ley Fundamental) y España (art. 20.1.b de la Constitución española), y que en principio comprendería la utilización de células-madre procedentes de embriones humanos fecundados in vitro. Tal intervención necesita un fundamento constitucional, que en este caso se busca en el deber de protección anejo a los derechos fundamentales de los que pueda ser titular el embrión, eventualmente destruido para la obtención de tales células: se invocan al efecto el derecho a la vida (art. 2.2 LF y art. $15 \mathrm{CE}$ ) y la dignidad humana (art. 1.1 LF y art. 10.1 CE). Las restricciones a la libertad de investigación podrían resultar así no sólo constitucionalmente legítimas, sino incluso inexcusables, en cuanto impuestas por la protección debida a otro derecho fundamental.

La vida humana y la dignidad, en cualquier caso, gozan de una protección constitucional diferenciada. En Alemania, mientras que la dignidad resulta de acuerdo con la Ley Fundamental intangible, y por ello se considera inadmi- 
sible cualquier ponderación que relativice su alcance, la vida humana es un derecho fundamental que puede entrar en colisión con otros bienes jurídicos. Dicho en otros términos, la injerencia en el derecho a la vida podría encontrar justificación, pero no la lesión de la dignidad. Por lo demás, la doctrina alemana acepta la declaración del Tribunal Constitucional según la cual "si existe vida humana, le corresponde dignidad" . Con ello, el comienzo de la protección constitucional coincide con el de la vida humana, pero su contenido se extiende no sólo a la protección de esa vida, sino también de la dignidad; un criterio que ofrece mayor riqueza de implicaciones morales y, como se ha señalado, consecuencias jurídicas menos flexibles.

Determinar el comienzo de la vida humana es tarea compleja, en la que el jurista está obligado a valorar datos científicos que tienden a presentar un proceso continuo de desarrollo; el momento relevante puede fijarse así en instantes diferentes, sin que la jurisprudencia constitucional haya dilucidado definitivamente la cuestión. Ya en la primera sentencia alemana sobre la interrupción voluntaria del embarazo, de 25 de febrero de 1975, el Tribunal Constitucional alemán afirma que el deber de protección del Estado existe sin duda, de acuerdo con los conocimientos acreditados de la biología y la fisiología, a partir del décimocuarto día posterior a la fecundación, cuando se produce la anidación del óvulo y la individuación del embrión ${ }^{4}$. En la segunda sentencia, dieciocho años más tarde, el Tribunal deja sin decidir si la vida humana comienza con la unión del espermatozoide y el óvulo, aunque incidentalmente tiende a reconocerlo ${ }^{5}$. Tan temprana protección de la vida humana como derecho fundamental parece sólo posible, en cualquier caso, en la medida en que los efectos de la protección sean susceptibles de ponderación.

Porque la protección derivada del derecho a la vida, ya lo hemos dicho, no convierte cualquier interrupción del proceso biológico en una intervención constitucionalmente ilegítima. Incluso el derecho a la vida del embrión, reconocido en Alemania, se considera compatible, por ejemplo, tanto con la interrupción voluntaria del embarazo como con ciertos métodos anticonceptivos que impiden la anidación del óvulo fecundado, especialmente en la medida en que con la protección del embrión entran en conflicto derechos de la mujer y otros bienes jurídicos merecedores de tutela. Del mismo modo, la libertad de investigación científica, orientada a la curación de enfermedades severas, podría proyectarse como fin legítimo para la eventual destrucción de embriones que ya no pueden ser implantados en el útero.

La dignidad tampoco queda afectada por el mero hecho de la destrucción del embrión; no toda intervención en el derecho a la vida es, por ello sólo, le-

\footnotetext{
${ }^{3}$ BVerGE 39, 1 [41]; BVerfGE 88, 203 [252].

${ }^{4}$ BverGE 39, 1 [37].

${ }^{5}$ BVerfGE 88, 203 [251]
} 
sión de la dignidad humana. La doctrina dominante y la jurisprudencia constitucional, a partir de una clásica formulación de Dürig que manifiestamente se apoya en el imperativo categórico kantiano, entienden que la dignidad queda comprometida cuando el ser humano es convertido en un simple objeto. De ahí deriva la prohibición de producir embriones con fines instrumentales, que inicialmente encuentra en Alemania un reconocimiento casi unánime. Cuando el embrión fecundado con fines reproductivos resulta sacrificado a fines de investigación, su mera existencia queda subordinada a intereses ajenos, en este caso los que mediatamente representa el investigador. Aún en el caso de que a la vida del embrión sobrante no le quepa ulterior desarrollo, y esta utilización le atribuya finalmente un sentido, lo cierto es que esa atribución de sentido sería instrumental, la propia de un objeto, y no autónoma. Parece que no cabe sino considerar tal hecho como un atentado contra la dignidad del embrión.

Lo cierto es, sin embargo, que la generosa invocación del art. 1.1 de la Ley Fundamental por parte del Tribunal Constitucional alemán ${ }^{6}$ no ha bloqueado los debates, si bien ha forzado a la doctrina a distinciones cada vez más sutiles, por ejemplo diferenciando entre la dignidad y las concretas pretensiones derivadas de su garantía jurídica, necesariamente relativas, y depurando la relación entre el deber de respeto (aspecto subjetivo o vinculación negativa) y el deber de protección (aspecto objetivo o vinculación positiva) comprendidos en tal garantía ${ }^{7}$.

De la dignidad de la persona a la que alude la Constitución española sería difícil extraer tan ricas consecuencias. El propio texto del art. 10.1 CE, en conexión con los valores superiores del art. 1.1 CE y con el fundamento de la Constitución "en la indisoluble unidad de la Nación española" (art. 2 CE), impide atribuir aquí a la dignidad de la persona el mismo papel que desempeña en Alemania la dignidad del hombre, reconocida en el art. 1.1 de la Ley Fundamental como norma fundacional del Estado y de su ordenamiento jurídico constitucional. La dignidad de la persona tampoco opera en España como

${ }^{6}$ Cfr. sólo D. Hömig, «Die Menschenwürdegarantie des Grundgesetzes in der Rechtsprechung der Bundesrepublik Deutschland», EuGRZ 2007, págs. 633 ss. (el autor fue ponente de la célebre sentencia sobre la Ley de Seguridad Aérea, BVerfGE 115, 118), y la más reciente Sentencia de 9 de febrero de 2010, que apura las consecuencias del vínculo entre la dignidad de la persona y el postulado del Estado social, http://www.bverfg.de/entscheidungen/ ls20100209_1bvl000109.html.

${ }^{7}$ Veánse por ejemplo U. Vosgerau, «Zur Kollision von Grundrechtsfunktionen», AöR 133, págs. 346 ss., y J. V. Bernstorff, «Pflichtenkollision und Menschenwürdegarantie. Zum Vorrang staatlicher Achtungspflichten im Normbereich von Art. 1 GG», Der Staat 47, págs. 21 ss. Sobre el debate suscitado en Alemania por la propuesta de diferenciar entre objeto y contenido de los derechos fundamentales véase J. Alguacil González-Aurioles, «Contenido, objeto y límites de los derechos a la luz de la reciente polémica alemana», Teoría y Realidad Constitucional 18, págs. 305 ss. 
derecho fundamental: el constituyente español, preocupado por dotar de una garantía precisa y diferenciada a los derechos fundamentales, excluyó la dignidad de la persona y el libre desarrollo de la personalidad del correspondiente catálogo, dejando ambos postulados al margen de las garantías previstas en los apartados 1 (garantía del contenido esencial) y 2 (recurso de amparo) del art. $53 \mathrm{CE}$, e incluso fuera del ámbito protegido por el procedimiento extraordinario de reforma constitucional (art. $168 \mathrm{CE}$ ). En la jurisprudencia constitucional existen resoluciones que ciertamente evocan la llamada Objektformel (SSTC 53/1985, 231/1988, 212/1996, 224/1999, $91 / 2000,192 / 2003$ ), pero no alcanzan a constituirse en línea orientadora para la determinación del contenido de la dignidad de la persona, que en cualquier caso puede quedar sometida a ponderación (STC 53/1985) o ser limitada con las reservas impuestas por el principio de proporcionalidad (STC 98/2000).

En España es por tanto preciso recurrir directamente al derecho a la vida para abordar tales cuestiones desde la perspectiva constitucional. Hemos señalado que los deberes de protección a cargo del Estado que se derivan del reconocimiento constitucional de los derechos fundamentales, y en concreto de la vida humana, permiten a la jurisprudencia constitucional, por ejemplo, controlar la despenalización de la interrupción voluntaria del embarazo. Tales deberes se hicieron derivar inicialmente en Alemania de la vinculación de los derechos concretos, y en particular del derecho a la vida, con la dignidad, articuladora del supuesto sistema de valores encarnado en los derechos fundamentales; luego ya se dotaron de un perfil dogmático propio y fueron radicados en cada uno de los derechos particulares, sin necesidad de apelar a la jurisprudencia de valores. También en España el Tribunal Constitucional configura en la STC 53/1985 un deber de protección de la vida humana ${ }^{8}$. Pero al efecto, aunque no invoca como complemento el valor de la dignidad de la persona, se siente en la necesidad de convertir la propia vida en valor superior. Un derecho elevado a tal rango, sin embargo, difícilmente puede ser sometido a ponderación; la STC 48/1996 afirma expresamente que "el derecho a la vida y a la integridad (...) tiene un carácter absoluto".

Con ello se dota a la protección de la vida de una rigidez que, como intuye la propia jurisprudencia, es incompatible con una concepción dilatada de su objeto y contenido. Justamente por eso la STC 53/1985 atribuye en España al nasciturus la cualidad de bien jurídico constitucionalmente protegido por el art. $15 \mathrm{CE}$, pero no le reconoce la titularidad del derecho a la vida. La STC 212/1996 enfatiza la negativa a reconocer al nasciturus un derecho fundamental, poniendo expresamente de manifiesto que el Tribunal pretende evitar que a este problema se aplique la noción de contenido esencial.

${ }^{8}$ Los votos particulares, por cierto, reflejan la amplia discusión acerca de las posibilidades y límites del correspondiente control del legislador a cargo de la jurisdicción constitucional. 
En cuanto al momento en el que surge ese menos preciso y más limitado deber de protección de la vida de quien, en realidad, no es titular del derecho a la vida, el Tribunal se limita a "precisar a) Que la vida humana es un devenir, un proceso que comienza con la gestación" (STC 53/1985). Más adelante, la STC 212/1996 entiende que el deber de protección no se proyecta sobre la vida del embrión como bien jurídico protegido por sí mismo, y precisamente desde el inicio de la gestación, sino en cuanto destinado a ser persona, futuro sujeto de los derechos fundamentales; de manera que "la cuestión relativa a la viabilidad o no de los embriones y fetos humanos (...) ocupa lógicamente una posición central". La ulterior STC 116/1999 vincula tal viabilidad con un dato objetivo, la transferencia del óvulo fecundado al útero materno; la viabilidad no es un juicio de posibilidad abstracta, sino una expectativa abierta por un proceso concreto de desarrollo. La protección corresponde, en fin, al embrión viable en cuanto implantado en el útero materno; y el embrión no viable no está protegido, ni siquiera en la forma debilitada de bien jurídico, por el art. 15 de la Constitución. Queda pendiente de explicar la afirmación de la STC 212/1996 conforme a la cual la dignidad de la persona (art. 10.1 CE) puede tener cierta proyección respecto de un embrión no viable, incapaz de "desarrollarse hasta dar lugar a un ser humano, a una «persona» en el fundamental sentido del art. 10.1 CE".

A la postre, pues, en España se ha eludido el valor absoluto de la dignidad y se escamotea en la argumentación el que se atribuye a la vida humana. El Derecho constitucional queda, en la práctica, al margen de este concreto debate sobre la investigación con células-madre de origen embrionario. En Alemania, el reconocimiento constitucional de la intangible dignidad del hombre y el rigor de la jurisprudencia al concretarla colocan a la doctrina ante la necesidad de refinar la elaboración dogmática para abrir paso a la argumentación concreta sobre posibilidades y límites.

III. Las diferencias en las regulaciones nacionales descansan sobre concepciones distintas de la dignidad humana, asentadas sobre la particular experiencia moral de cada sociedad y consagradas en el momento constituyente. Tal experiencia bien puede consagrar avances no revisables, como la prohibición de la esclavitud y de la tortura; pero también debe ser actualizada si ha de servir de criterio orientador frente a los nuevos retos: "qué signifique el mandato de respetar la dignidad resultará de la evolución histórica y del nivel de conciencia. Ni las ideas de los padres de la Constitución ni las interpretaciones actuales pueden pretender una validez intemporal" ". El contenido de la Constitución queda codeterminado por los ciudadanos, en cuanto sociedad

${ }^{9}$ E. Benda, «Dignidad humana y derechos de la personalidad», en Benda, Maihofer, Vogel, Hesse, Heyde, Manual de Derecho constitucional, Madrid: Marcial Pons/Instituto Vasco de Administración Pública, 2001, pág. 136. 
abierta de intérpretes de la Constitución ${ }^{10}$, en el debate público en torno a la interpretación de los principios constitucionales.

Ahora bien, la consiguiente apertura de los conceptos constitucionales a una concreción dinámica en el marco de los desarrollos sociales, culturales y científicos no constituye un argumento a favor de la extensión del ámbito material de protección constitucional tan lejos como pretenda cualquiera de las concepciones representadas en el foro público. Si bien pueden acogerse las más variadas demandas de protección de los derechos fundamentales como parte integrante del foro público de relevancia constitucional (presencia de los derechos fundamentales en el proceso constitucional democrático), la tutela jurídica material proporcionada por la Constitución debe reservarse al núcleo de la garantía consolidado en la conciencia de cada momento histórico (garantía de los derechos fundamentales frente al resultado del proceso constitucional democrático).

La dignidad del hombre no puede operar, en definitiva, como expresión de incertidumbres provisionales; su pretensión de intangibilidad no debe quedar expuesta a la erosión del tiempo. Sólo el resultado de las experiencias y de los debates, contemplado con perspectiva histórica, estará en condiciones de consolidar un nuevo umbral de protección de la dignidad. Una generosa protección constitucional material de valores absolutos no conduce, en efecto, a la discusión abierta de las diferentes posiciones jurídicas sub specie constitutionis, sino que ciega los debates. Tal ceguera quizá reconforte nuestras ansias de seguridad, pero no nos iluminará acerca de los procesos que la ciencia ya ha puesto en marcha y de las expectativas que despiertan para la humanidad.

Ello no supone adoptar una perspectiva (optimista, resignada o cínica) para la cual sería necesario admitir como jurídicamente lícito todo lo técnicamente posible. Ahora bien, someter al parámetro normativo intemporal de la dignidad humana utopías y antiutopías construidas al amparo del cine o de la literatura, para luego proyectar las conclusiones sobre los desarrollos actuales, vistos por cierto como un mero estadio transitorio hacia tales horizontes, no parece un procedimiento sensato de prevención de riesgos, sino más bien un recurso dialéctico poco refinado. Más fructífero que la invocación abstracta de la fórmula que condensa la noción kantiana de dignidad sería un análisis diferenciado de los argumentos relevantes a la vista de cada problema concreto: el diagnóstico preimplantatorio para la selección de embriones o incluso de gametos plantea cuestiones diferentes si se orienta a eliminar los dañados por enfermedades genéticas graves, a ensayar terapias genéticas avanzadas o a seleccionar los más aptos para una ulterior donación de órganos o tejidos en beneficio de un familiar enfermo.

${ }^{10}$ P. Häberle, Die Verfassung des Pluralismus. Studien zur Verfassungstheorie der offenen Gesellschaft, Königstein/Ts.: Athenäum, 1980. 


\section{BIBLIOGRAFÍA CITADA}

Alguacil GonZÁlez-Aurioles, J., «Contenido, objeto y límites de los derechos a la luz de la reciente polémica alemana», Teoría y Realidad Constitucional 18, 2006, págs. 305 ss.

BENDA, E., «Dignidad humana y derechos de la personalidad», en BENDA, Mainofer, Vogel, Hesse, HeYde, Manual de Derecho constitucional, Madrid: Marcial Pons/Instituto Vasco de Administración Pública, 2001, págs. 117 ss.

BERNSTORFF, J. V., «Pflichtenkollision und Menschenwürdegarantie. Zum Vorrang staatlicher Achtungspflichten im Normbereich von Art. 1 GG», Der Staat 47, págs. 21 ss.

Dederer, H. G., «Die Garantie der Menschenwürde (Art. 1 Abs. 1 GG). Dogmatische Grundfragen auf dem Stand der Wissenschaft», JöR (NF) 57, págs. 89 ss.

GrIMM, D., Denninger, E., Derecho constitucional para la sociedad multicultural (ed. por I. Gutiérrez Gutiérrez), Madrid: Trotta, 2007.

GuTIÉRREZ GUTIÉRREZ, I., «El debate alemán sobre la investigación con células-madre de origen embrionario», Teoría y Realidad Constitucional $\mathrm{n}^{\circ}$ 10-11, 2002-2003, págs. 533 ss.

- Dignidad de la persona y derechos fundamentales, Madrid-Barcelona: Marcial Pons, 2005.

HÄBERLE, P., Die Verfassung des Pluralismus. Studien zur Verfassungstheorie der offenen Gesellschaft, Königstein/Ts.: Athenäum, 1980.

HöMIG, D., «Die Menschenwürdegarantie des Grundgesetzes in der Rechtsprechung der Bundesrepublik Deutschland», EuGRZ, 2007, págs. 633 ss.

McCRudden, Chr., «Human Dignity and Judicial Interpretation of Human Rights», EJIL 19, 2008, págs. 655 ss.

NetTesheIM, M., «Die Garantie der Menschenwürde zwischen metaphysischer Überhöhung und bloßem Abwägungstopos», AöR 130, 2005, págs. $71 \mathrm{ss}$.

Peters, A., Aznar, M., Gutiérrez, I. (eds.), La constitucionalización de la Comunidad internacional, Valencia: Tirant lo Blanch, 2010.

VosGERAU, U., «Zur Kollision von Grundrechtsfunktionen», AöR 133, 2008, págs. 346 ss. 